\title{
Effects of botulinum toxin type A for spastic foot in post-stroke patients enrolled in a rehabilitation program
}

\author{
Efeitos da toxina botulínica tipo A no pé espástico em pacientes pós-acidente \\ vascular encefálico inseridos em programa de reabilitação \\ Leonardo Halley Carvalho Pimentel',2, Francisco José Alencar', Leonardo Raphael Santos Rodrigues', \\ Francisca Cléa Florenço de Sousa², João Batista Mendes Teles ${ }^{3}$
}

\begin{abstract}
The objective of this study was to evaluate the effects of botulinum toxin type A (BTX-A) on spastic foot in stroke patients in a rehabilitation program. Method: Hemiparetic stroke patients $(n=21)$ enrolled in a rehabilitation program were divided into two groups. The first group ( $n=11)$ received a total of $300 \mathrm{UI}$ BTX-A, and the second group $(n=10)$ received $100 \mathrm{UI}$ BTX-A. All patients were assessed at baseline and 2, 4, 8 and 12 weeks after injection for Modified Ashworth Score, time walking 10 meters, and the Functional Independence Measure (mFIM) motor score. Results: The higher-dose group exhibited a significant improvement in spasticity, and both groups showed an improvement in time walking 10 meters and mFIM, with no significant differences between them. Conclusions: Our findings suggest that gains in gait velocity and functional independence were not correlated to BTX-A dose.
\end{abstract}

Keywords: botulinum toxin type A, stroke, spasticity.

\section{RESUMO}

O objetivo deste estudo foi avaliar os efeitos da toxina botulínica tipo A (TXB-A) sobre a espasticidade de membro inferior em pacientes pós-AVE em reabilitação. Método: 21 pacientes hemiparéticos foram divididos em dois grupos que receberam doses de TXB-A de 300UI (Grupo 1) e 100UI (Grupo 2) e foram avaliados antes da injeção e 2, 4, 8 e 12 semanas após, quanto à escala de Ashworth modificada, tempo para andar 10 metros e escore motor da Medida de Independência Funcional (MIFm). Resultados: 0 grupo que utilizou dose mais alta teve melhora significativa da espasticidade. Ambos os grupos tiveram melhora do tempo para andar 10 metros e da MIFm sem diferença significativa entre eles. Conclusões: A melhora da velocidade de marcha e da independência funcional não foram correlacionadas com a dose de TXB-A na amostra analisada.

Palavras-chave: toxina botulínica tipo A, acidente vascular cerebral, espasticidade.

Only 25 percent of stroke patients return to the everyday level of participation and physical functioning of communitymatched persons who have not experienced a stroke ${ }^{1,2}$. Not surprisingly, quality of life tends to be higher among patients with better functioning than those with worse functioning ${ }^{2,3}$. Ambulation and activities of daily living (ADL) are major goals in stroke rehabilitation programs, and patient prognosis is associated with several variables ${ }^{4}$.

Spasticity is one of the factors that affect the process of functional rehabilitation in stroke. Spasticity arises because of the loss of myotatic reflex inhibition that results from an upper motor neuron lesion ${ }^{5}$. Botulinum toxin type A (BTX-A) is one of the most potent biological toxins that acts by blocking neuromuscular transmission by inhibiting acetylcholine release, and it is a well-known treatment for post-stroke spasticity, despite some variations among dose protocols ${ }^{6}$.

The Functional Independence Measure (FIM) is a scale employed worldwide to assess independence levels in different conditions, including stroke? The scale is subdivided into motor Functional Independence Measure (mFIM) and

${ }^{1}$ Centro Integrado de Reabilitação, Teresina PI, Brazil;

${ }^{2}$ Departamento de Fisiologia e Farmacologia, Universidade Federal do Ceará, Fortaleza CE, Brazil;

${ }^{3}$ Departamento de Medicina Comunitária, Universidade Federal do Piauí, Teresina PI, Brazil.

Correspondence: Leonardo Halley Carvalho Pimentel; Avenida Higino Cunha 1515;64014-220 Teresina PI - Brasil; E-mail: leonardo.pimentel@ceir.org.br

Conflict of interest: There is no conflict of interest to declare.

Received 22 March 2013; Received in final form 12 September 2013; Accepted 19 September 2013. 
cognitive scores. FIM measures the physical assistance or supervision needed for self-care using scores for toilet, dressing, bathing, eating, and mobility ${ }^{2}$.

Our objective was to evaluate the effects of lower-limb BTX-A injections in post-stroke hemiparetic patients on spasticity, gait velocity, and motor functional independence during participation in a rehabilitation program.

\section{METHOD}

This study was a randomized, prospective, double-blind trial. Patients were recruited from a reference rehabilitation center in Teresina, Brazil, if they had a diagnosis of stroke (ischemic or hemorrhagic) with a post-stroke period of at least 6 months, hemiparesis with spastic equinus foot (Ashworth score 3 or 4 in a range from 0 to 5), were ambulant with or without assistance or devices, were available to attend rehabilitation therapies activities at least 4 days/week in the next 3 months, and were able and willing to perform the required assessments. Patients with dementia or global or comprehension aphasias were excluded, as were individuals with a history of BTX-A injection or anticoagulant therapy. Informed consent was obtained from all patients enrolled. The study was approved by the regional institutional research ethics committee.

The first investigator interviewed all patients about their clinical and demographic characteristics (age, gender, time since stroke, stroke type, and hemiparesis side) and managed clinical assessments at baseline and during all phases of the study. Patients were randomized into two groups by the second investigator. The third investigator then injected BTX-A into every patient included in the study.

The first group received a 300UI BTX-A injection distributed thus: a) 100 UI into each head of the gastrocnemius, divided into two points: the first point into the midbelly and the other one about $5 \mathrm{~cm}$ proximally toward the popliteal fossa; b) 100 UI into soleus, divided into two points from about 2 $\mathrm{cm}$ of the calf midline bilaterally below the distal gastrocnemius protuberance. The second group received 100 UI BTX-A distributed into the midbelly of both heads of gastrocnemius. The injection sites were determined according to palpation and anatomic landmarks ${ }^{8,9}$. A constant dilution (100 units in $2 \mathrm{ml} \mathrm{0.9 \%} \mathrm{saline,} \mathrm{Botox} \mathrm{[Allergan,} \mathrm{Irvine,} \mathrm{CA])} \mathrm{was} \mathrm{used} \mathrm{for}$ every patient, and the total dose was equally distributed in every injected muscle point.

Throughout the entire study, all patients from both groups were enrolled in a rehabilitation program and performed physical activities (aquatic physiotherapy and/or motor physiotherapy, with the goals of gait training and improvement in range of motion, and occupational therapy with the goal of training ADL). These therapies were attended at least 4 days/ week for at least 40 minutes/day.
Clinical assessments were made by the first investigator at baseline and 2, 4, 8, and 12 weeks after BTX-A injection, according to the following variables: a) Ashworth score: ankle muscle tone was evaluated according to the modified Ashworth Scale in a range from 0 to 5; b) time walking 10 meters: time to walk 10 meters with or without assistance and/ or devices, measured in seconds; and c) mFIM: FIM score, considering only the parameters of motor assessment in a range from 13 to 91 .

Patients who missed at least one evaluation of the followup were excluded.

\section{Statistical analysis}

Kolmogorov-Smirnov tests were performed to evaluate normality of the data and to choose between parametric and nonparametric tests. The two groups were compared with regard to categorical variables (demographic and clinical) using Student's $t$-test, the Mann-Whitney $U$ test, and Fisher's exact test (the latter was chosen because of the existence of frequencies $<5$ ), as appropriate. The effects of BTX-A on the two groups were compared using Student's $t$-test for time walking 10 meters and mFIM (with Pearson's correlation to analyze associations) and the Mann-Whitney $U$ test for Ashworth score (with Spearman's correlation to analyze associations). A significance level of 0.05 was employed for all statistical tests. All analyses were performed using Statistical Package for Social Sciences software for Windows, version 12.0 (SPSS, Chicago, IL).

\section{RESULTS}

Initially 30 patients with spastic hemiparesis after stroke were screened. Four did not meet the inclusion criteria, and five qualified patients were lost during follow-up. The clinical and demographic baseline characteristics of the remaining population are displayed in Table 1 . As a result of randomization, there were no significant differences between the two groups with regard to age, gender, affected side, or symptom duration. The mean mFIM score at baseline was $65.3( \pm 15.1)$ in group 1 and $70.0( \pm 9.4)$ in group $2(p>0.05)$.

Table 2 lists the mean Ashworth scores, time to walk 10 meters, and mFIM variables at baseline and follow-up. There were no significant differences between the two groups in relation to time to walking 10 meters or mFIM at baseline, or at any follow-up evaluation. Considering the Ashworth score, there was a significant difference between the two groups after 8 and 12 weeks of BTX-A injection, with a significant improvement in group 1 at both time points. These results are summarized in Table 3.

No severe adverse effects were reported during the study. Two patients from Group 1 experienced mild calf pain just after injection, but this disappeared in 2-3 days. 
Both groups exhibited successive improvements for mFIM in all evaluations, with no significant difference (Figure).

There was a positive correlation between gait velocity and $\mathrm{mFIM}$ at baseline and at every follow-up evaluation in Group

Table 1. Clinical and demographical characteristics at baseline.

\begin{tabular}{|c|c|c|c|}
\hline Variables (SD) & $\begin{array}{c}\text { Group } 1 \\
(n=11)\end{array}$ & $\begin{array}{c}\text { Group } 2 \\
(n=10)\end{array}$ & $\begin{array}{c}\mathrm{p} \text {-value } \\
\text { (two-tailed) }\end{array}$ \\
\hline Mean age in years & $50.5( \pm 6.8)$ & $47.9( \pm 3.8)$ & 0.309 \\
\hline Median & 51 & 48 & \\
\hline [Range] & [34-59] & {$[42-54]$} & \\
\hline Gender & & & 0.395 \\
\hline Female & 7 & 4 & \\
\hline Male & 4 & 6 & \\
\hline $\begin{array}{l}\text { Mean time since } \\
\text { stroke in months }\end{array}$ & $41.6( \pm 63.4)$ & $34.5( \pm 33.8)$ & 0.721 \\
\hline Median & 11 & 16 & \\
\hline [Range] & [6-193] & [6-89] & \\
\hline Stroke type & & & 1.000 \\
\hline Ischemic & 7 & 7 & \\
\hline Hemorrhagic & 4 & 3 & \\
\hline Hemiparesis side & & & 0.670 \\
\hline Right & 5 & 6 & \\
\hline Left & 6 & 4 & \\
\hline $\begin{array}{l}\text { Mean time walking } 10 \\
\text { meters before BTX-A }\end{array}$ & $35.7( \pm 7.3)$ & $34.9( \pm 6.1)$ & 0.782 \\
\hline Median & 34 & 33.5 & \\
\hline [Range] & {$[27-48]$} & {$[28-45]$} & \\
\hline $\begin{array}{l}\text { Mean mFIM before } \\
\text { BTX-A }\end{array}$ & $65.3( \pm 15.1)$ & $70.0( \pm 9.4)$ & 0.406 \\
\hline Median & 69 & 68 & \\
\hline [Range] & [41-88] & [61-86] & \\
\hline
\end{tabular}

SD: standard deviation; BTX-A: botulinum toxin type A; mFIM: motor Functional Independence Measure.
1 (r range from 0.851 to $0.928, \mathrm{p} \leq 0.001$ ) and Group 2 ( $\mathrm{r}$ range from 0.675 to $0.888, \mathrm{p} \leq 0.032$ ).

\section{DISCUSSION}

The FIM scale is widely used to assess functional improvement in patients with various physical limitations,

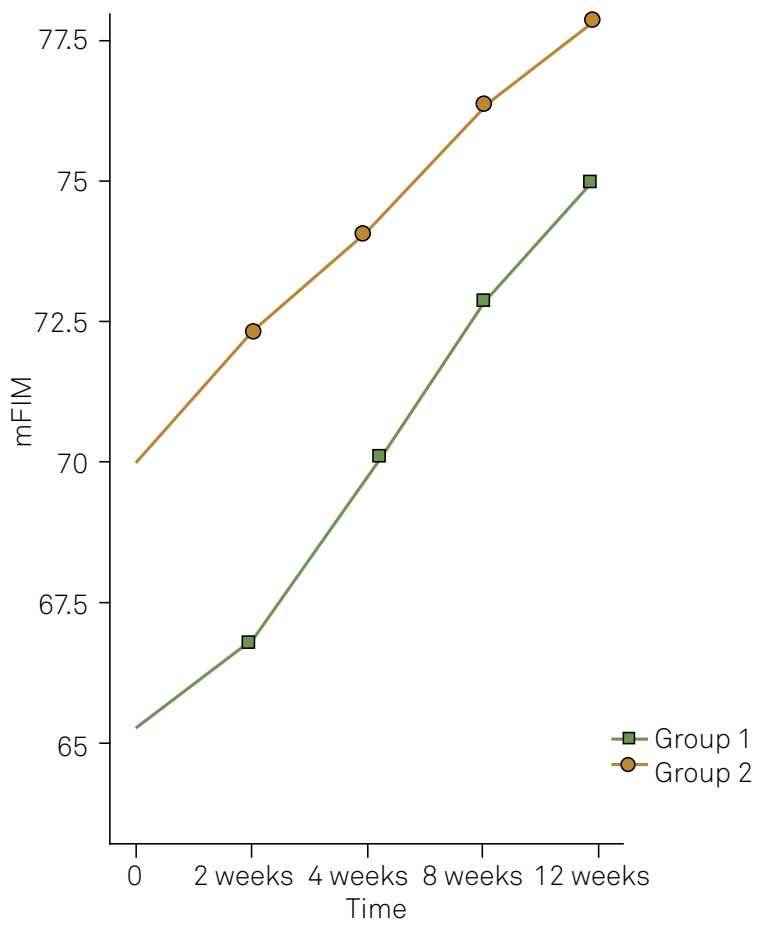

Figure. Course of motor Functional Independence Measure (mFIM) at follow-up evaluation.

Table 2. Mean values (SD) of clinical assessment variables at baseline and follow-up evaluations.

\begin{tabular}{|c|c|c|c|c|c|c|c|c|c|c|}
\hline \multirow{2}{*}{$\begin{array}{l}\text { Variables } \\
\text { Mean (SD) }\end{array}$} & \multicolumn{2}{|c|}{ Baseline } & \multicolumn{2}{|c|}{2 weeks } & \multicolumn{2}{|c|}{4 weeks } & \multicolumn{2}{|c|}{8 weeks } & \multicolumn{2}{|c|}{12 weeks } \\
\hline & Group 1 & Group 2 & Group 1 & Group 2 & Group 1 & Group 2 & Group 1 & Group 2 & Group 1 & Group 2 \\
\hline $\begin{array}{l}\text { Modified ashworth } \\
\text { score }\end{array}$ & $\begin{array}{c}3.3 \\
( \pm 0.5)\end{array}$ & $\begin{array}{c}3.4 \\
( \pm 0.5)\end{array}$ & $\begin{array}{c}3.0 \\
( \pm 0.8)\end{array}$ & $\begin{array}{c}3.3 \\
( \pm 0.7)\end{array}$ & $\begin{array}{c}2.0 \\
( \pm 1.0)\end{array}$ & $\begin{array}{c}2.7 \\
( \pm 0.8)\end{array}$ & $\begin{array}{c}1.7 \\
( \pm 0.8)\end{array}$ & $\begin{array}{c}2.7 \\
( \pm 0.8)\end{array}$ & $\begin{array}{c}1.6 \\
( \pm 0.9)\end{array}$ & $\begin{array}{c}3.3 \\
( \pm 0.7)\end{array}$ \\
\hline $\begin{array}{l}\text { Time walking } 10 \\
\text { meters }\end{array}$ & $\begin{array}{l}35.73 \\
( \pm 7.29)\end{array}$ & $\begin{array}{l}34.90 \\
( \pm 6.06)\end{array}$ & $\begin{array}{l}35.82 \\
( \pm 7.49)\end{array}$ & $\begin{array}{l}34.90 \\
( \pm 6.30)\end{array}$ & $\begin{array}{l}35.09 \\
( \pm 6.76)\end{array}$ & $\begin{array}{l}32.80 \\
( \pm 6.53)\end{array}$ & $\begin{array}{l}31.18 \\
( \pm 7.01)\end{array}$ & $\begin{array}{l}31.00 \\
( \pm 5.50)\end{array}$ & $\begin{array}{l}30.82 \\
( \pm 7.18)\end{array}$ & $\begin{array}{c}31.90 \\
( \pm 5.63)\end{array}$ \\
\hline $\mathrm{mFIM}$ & $\begin{array}{c}65.27 \\
( \pm 15.10)\end{array}$ & $\begin{array}{l}70.00 \\
( \pm 9.39)\end{array}$ & $\begin{array}{c}66.82 \\
( \pm 15.48)\end{array}$ & $\begin{array}{l}72.30 \\
( \pm 9.71)\end{array}$ & $\begin{array}{c}69.73 \\
( \pm 15.59)\end{array}$ & $\begin{array}{l}74.10 \\
( \pm 8.75)\end{array}$ & $\begin{array}{c}72,82 \\
( \pm 15.57)\end{array}$ & $\begin{array}{l}76.30 \\
( \pm 9.36)\end{array}$ & $\begin{array}{c}75.09 \\
( \pm 14.90)\end{array}$ & $\begin{array}{c}77.90 \\
( \pm 10.06)\end{array}$ \\
\hline
\end{tabular}

SD: standard deviation; mFIM: motor Functional Independence Measure.

Table 3. Analysis of clinical assessment variables at baseline and follow-up evaluations.

\begin{tabular}{|c|c|c|c|c|c|c|}
\hline & \multicolumn{2}{|c|}{ Ashworth score } & \multicolumn{2}{|c|}{ Time walking $10 \mathrm{~m}$} & \multicolumn{2}{|c|}{$\mathrm{mFIM}$} \\
\hline & $\mathrm{t}$ & $\mathrm{p}$-value & $\mathrm{t}$ & $p$-value & $\mathrm{t}$ & $\mathrm{p}$-value \\
\hline Baseline & -0.593 & 0.560 & 0.281 & 0.782 & -0.851 & 0.406 \\
\hline Week 2 & -1.533 & 0.358 & 0.302 & 0.766 & -0.960 & 0.349 \\
\hline Week 4 & -1.711 & 0.098 & 0.788 & 0.440 & -0.781 & 0.444 \\
\hline Week 8 & -2.616 & $0.012^{\star}$ & 0.066 & 0.948 & -0.613 & 0.547 \\
\hline Week 12 & -5.318 & $0.0001 *$ & -0.381 & 0.707 & -0.501 & 0.622 \\
\hline
\end{tabular}

* $\mathrm{p}<0.05 . \mathrm{mFIM}$ : motor Functional Independence Measure. 
including those with sequelae of stroke. The FIM consists of 18 items that can be classified into two groups to assess both motor function (13 items) and cognitive function ( 5 items $)^{10}$. Reliability coefficients for motor items of the FIM scale are generally larger than those for the items in the cognitive subscale $^{11}$. A recent study suggested that the FIM motor score and the patient's performance in ADLs are important predictors for post-stroke prognosis ${ }^{12}$.

Spasticity results in limited functional capacity and increased inactivity after stroke. The modified Ashworth Scale, which evaluates the sum of the interference of biomechanical and neural components in passive stretching, is the most common tool used for grading spasticity after a stroke. The treatment of spasticity with BTX-A and physical therapy is suggested to improve functionality in patients with marked spasticity after a stroke ${ }^{13}$.

Gait restoration is a major goal of neurological rehabilitation. Intensive gait training in patients after more than 6 months of injury results in significant gains in the FIM scale and in life-role participation ${ }^{14}$. Before starting therapy, a comprehensive assessment is necessary to evaluate deficits and remaining functions, and a wide variety of therapeutic procedures have to be adapted to the individual situation ${ }^{15}$. The improvement in gait pattern tends to be accompanied by increased in performing ADLs. In this study, the time to walk 10 meters was associated with the motor functional independence score in all phases.

Frequent therapy attendance is important for successful rehabilitation. In a study of patients admitted to a specialized Canadian rehabilitation service that involved an average 37 minutes/day of therapies (including physiotherapy and occupational therapy) FIM gain was associated with length of stay and the total amount of time in occupational thera$\mathrm{py}^{16}$. Persons 55 years or older who had a stroke, regardless of race or ethnicity, seem to benefit from inpatient medical rehabilitation, with the most functional gains occuring during therapy and in the first month after discharge ${ }^{17}$.

In the last few decades BTX-A has been described for the treatment of equinus foot following stroke ${ }^{18,19}$. It was reported to induce significant improvements in the Ashworth score using the BTX-A, as well as in gait speed, but the latter was not significant ${ }^{19}$. Another study reported that the use of BTX-A for equinovarus foot in lower-limb post-stroke spasticity was associated with a small but statistically significant increase in gait velocity ${ }^{20}$. BTX treatment results in improved joint mobility and ankle kinematics and, in some patients, increases in positive work, suggesting better gait performance ${ }^{21}$.
BTX-A reduces the degree of spasticity, but the effects on the parameters of gait and ADLs remain controversial. A study using a total dose of 300 UI BTX-A in spastic leg muscles of 47 patients with stroke showed a moderate but significant reduction in spasticity and a slight increase in gait velocity and step length, with great variability among patients $^{22}$. A Japanese trial reported a significant reduction in lower-limb spasticity in post-stroke patients using $300 \mathrm{UI}$ BTX-A compared with placebo at weeks 4, 6, and 8 after application. In one trial, gait speed revealed no significant treatment differences but showed a tendency towards improvement with BTX-A $\mathrm{A}^{23}$.

Use of an ankle-foot orthosis increases ankle dorsiflexion during the swing phase and does not reduce the benefits gained by the use of BTX in the stance phase ${ }^{24}$. Prolonged stretching of spastic muscles after BTA injection in patients wearing an ankle-foot cast overnight for 4 months yielded long-lasting therapeutic benefit, enhancing the effects of the toxin alone $e^{25}$.

The effect of BTX-A on upper-limb spasticity is best described. A Brazilian study showed functional improvement in patients with post-stroke hemiparesis who received BTX-A in the upper limb, including improvement on the motor subscale of the $\mathrm{FIM}^{26}$. A systematic review of the use of BTX for spasticity after stroke in adults showed that the overall effect on upper-limb spasticity was positive, with significant improvements observed in the periods from 3-6 weeks to 9-12 weeks after initiating treatment. This same study could not establish the efficacy of BTX in treating lower-limb spasticity ${ }^{27}$.

We found significant improvements in the group treated with the higher dose of BTX-A at follow-up weeks 8 and 12 . The reduction in spasticity in the last phases of the evaluation was expected based on results from previous studies in patients with stroke ${ }^{28}$ and cerebral palsy ${ }^{29,30}$. The use of BTX-A reduces lower-limb spasticity in several conditions involving pyramidal system injury, including stroke $e^{6,28}$.

Regarding mFIM score and time walking 10 meters, there was no significant difference between the groups at any time point. There was progressive improvement in these parameters in both groups throughout the study. The high dose of BTX-A had a beneficial effect on spasticity, but this was not associated with improvements in functional motor pattern or gait speed in the analyzed sample. The inclusion of post-stroke spastic hemiparetic patients in a rehabilitation program with a regular schedule of supervised physical activities remains important for improvements in functional independence.

\section{References}

1. Lai SM, Studenski S, Duncan PW, Perera S. Persisting consequences of stroke measured by the Stroke Impact Scale. Stroke 2002;33:1840-1844.
Dobkin BH. Clinical practice. Rehabilitation after stroke. N Engl J Med 2005;352:1677-1684. 
3. Samsa GP, Matchar DB. How strong is the relationship between functional status and quality of life among persons with stroke? J Rehabil Res Dev 2004;41:279-282.

4. Sánchez-Blanco I, Ochoa-Sangrador C, López-Munaín L, IzquierdoSánchez M, Fermoso-Garcia J. Predictive model of functional independence in stroke patients admitted to a rehabilitation programme. Clin Rehabil 1999;13:464-475.

5. Gomes C, Carvalho AA, Campos RC, Gagliardi RJ, Lianza S. Reabilitação em hemiplegia. In: Lianza S (Ed). Medicina de Reabilitação. Rio de Janeiro: Guanabara Koogan, 2001:265-280.

6. Ozcakir S, Sivrioglu K. Botulinum toxin in post-stroke spasticity. Clin Med Res 2007;5:132-138.

7. Eilertsen TB, Kramer AM, Schlenker RE, Hrincevich CA. Application of functional independence measure-function related groups and resource utilization groups-version III systems across post acute settings. Med Care 1998;36:695-705.

8. Parratte B, Tatu L, Vuillier F, Diop M, Monnier G. Intramuscular distribution of nerves in the human triceps surae muscle: anatomical bases for treatment of spastic drop foot with botulinum toxin. Surg Radiol Anat 2002;24:91-96.

9. Van Campenhout A, Molenaers G. Localization of the motor endplate zone in human skeletal muscles of the lower limb: anatomical guidelines for injection with botulinum toxin. Dev Med Child Neurol 2011;53:108-119.

10. Linacre JM, Heinemann AW, Wright BD, Granger CV, Hamilton BB. The structure and stability of the Functional Independence Measure. Arch Phys Med Rehabil 1994;75:127-132.

11. Ottenbacher KJ, Hsu Y, Granger CV, Fiedler RC. The reliability of the functional independence measure: a quantitative review. Arch Phys Med Rehabil 1996; 77:1226-1232.

12. Gialanella B, Santoro R, Ferlucci C. Predicting outcome after stroke: the role of basic activities of daily living. Eur $J$ Phys Rehabil Med 2012;48:1-2.

13. Sommerfeld DK, Gripenstedt U, Welmer AK. Spasticity after stroke: an overview of prevalence, test instruments, and treatments. Am J Phys Med Rehabil 2012;91:814-820

14. Pundik S, Holcomb J, McCabe J, J Daly J. Enhanced life-role participation in response to comprehensive gait training in chronicstroke survivors. Disabil Rehabil 2012;34:1535-1539.

15. Mauritz KH. Gait training in hemiplegia. Eur J Neurol 2002;9:S23-2S9.

16. Foley N, McClure JA, Meyer M, Salter K, Bureau Y, Teasell R. Inpatient rehabilitation following stroke: amount of therapy received and associations with functional recovery. Disabil Rehabil 2012;34:2132-2138.

17. Berges IM, Kuo YF, Ottenbacher KJ, Seale GS, Ostir GV. Recovery of functional status after stroke in a tri-ethnic population. PM R 2012;4:290-295.
18. Dengler R, Neyer $U$, Wohlfarth $K$, Bettig $U$, Janzik $H H$. Local botulinum toxin in the treatment of spastic drop foot. $J$ Neurol 1992;239:375-378.

19. Burbaud P, Wiart L, Dubos JL, et al. A randomised, double blind, placebo controlled trial of botulinum toxin in the treatment of spastic foot in hemiparetic patients. J Neurol Neurosurg Psychiatry 1996;61:265-269.

20. Foley N, Murie-Fernandez M, Speechley M, Salter K, Sequeira K, Teasell R. Does the treatment of spastic equinovarus deformity following stroke with botulinum toxin increase gait velocity? A systematic review and meta-analysis. Eur J Neurol 2010;17:1419-1427.

21. Novak AC, Olney SJ, Bagg S, Brouwer B. Gait changes following botulinum toxin A treatment in stroke. Top Stroke Rehabil 2009;16:67-376.

22. Rousseaux M, Compère $S$, Launay MJ, Kozlowski O. Variability and predictability of functional efficacy of botulinum toxin injection in leg spastic muscles. J Neurol Sci 2005;232:51-57.

23. Kaji R, Osako Y, Suyama K, et al. Botulinum toxin type A in post-stroke lower limb spasticity: a multicenter, double-blind, placebo-controlled trial.J Neurol 2010;257:1330-1337.

24. Pradon D, Hutin E, Khadir S, Taiar R, Genet F, Roche N. A pilot study to investigate the combined use of Botulinum toxin type-a and ankle foot orthosis for the treatment of spastic foot in chronic hemiplegic patients. Clin Biomech 2011;26:867-872.

25. Farina S, Migliorini C, Gandolfi M, et al. Combined effects of botulinum toxin and casting treatments on lower limb spasticity after stroke. Funct Neurol 2008;23:87-91.

26. Cardoso E, Pedreira G, Prazeres A, Ribeiro N, Melo A. Does botulinum toxin improve the function of the patient with spasticity after stroke? Arq Neuropsiquiatr 2007;65:592-595.

27. Elia AE, Filippini G, Calandrella D, Albanese A. Botulinum neurotoxins for post-stroke spasticity in adults: a systematic review. Mov Disord 2009;24:801-812

28. Bayram S, Sivrioglu K, Karli N, Ozcan O. Low-dose botulinum toxin with short-term electrical stimulation in post-stroke spastic drop foot: a preliminary study. Am J Phys Med Rehabil 2006;85:75-81.

29. Kwon JY, Hwang JH, Kim JS. Botulinum toxin a injection into calf muscles for treatment of spastic equinus in cerebral palsy: a controlled trial comparing sonography and electric stimulationguided injection techniques: a preliminary report. Am J Phys Med Rehabil 2010;89:279-286.

30. Sätilä H, Pietikäinen T, lisalo T, et al. Botulinum toxin type A injections into the calf muscles for treatment of spastic equinus in cerebral palsy: a randomized trial comparing single and multiple injection sites. Am J Phys Med Rehabil 2008;87:386-394. 